https://doi.org/10.38049/issn.2317-0875v26n2p.136-152 www.periodicos.unimontes.br/index.php/caminhosdahistoria

\title{
NARRATIVAS SOBRE A SÍNDROME PÓS-PÓLIO EM ASSOCIAÇÕES DE PACIENTES DO BRASIL E DA ESPANHA NOS MEIOS DIGITAIS
}

\author{
Danielle Souza Fialho da Silva ${ }^{1}$
}

Recebido em: 24/04/2021

Aprovado em: 26/05/2021

\begin{abstract}
Resumo: A Síndrome Pós-poliomielite (SPP) é uma patologia que afeta pessoas que tiveram pólio muitos anos depois da doença aguda. É considerada uma doença crônica e rara e seus sintomas caracterizam-se por fraqueza muscular, fadiga intensa e dores musculares e articulares, entre outros sintomas. O objetivo deste artigo é compreender que narrativas sobre a doença são divulgadas pelas associações de pacientes com Síndrome Pós-pólio e seus usos nos meios digitais. Analisaremos duas organizações de pacientes, uma do Brasil e uma da Espanha, a saber: a Associação Brasileira de Síndrome Pós-poliomielite (Abraspp), fundada em 2004 em São Paulo, Brasil, e a Asociación Afectados de Polio y Síndrome Post-polio, fundada em 2000 em Madrid, Espanha. Em nosso estudo qualitativo, analisamos as páginas institucionais de ambas as associações que se encontram em suportes digitais com acesso aberto. Tanto a Abraspp quanto a Asociación Afectados de Polio y Sindrome Post-polio sinalizam como papel principal de sua associação o caráter de divulgadoras de informações sobre a síndrome, tomando para o coletivo a co-elaboração de políticas inclusivas e defesa de direitos de pessoas com deficiência. Foi observado que nas fontes digitais analisadas das associações a SPP não é encampada como síndrome rara.
\end{abstract}

Palavras-chave: Síndrome Pós-Pólio; Associações de pacientes; Meios digitais, ativismo, doença rara

\section{NARRATIVAS SOBRE EL SÍNDROME POST-POLIO EN ASOCIACIONES DE ENFERMOS EN BRASIL Y ESPAÑ̃ EN MEDIOS DIGITALES}

Resumen: El síndrome Post-poliomielitis (SPP) es una enfermedad que afecta a las personas que tuvieron poliomielitis muchos años después de la enfermedad aguda. Es considerada una enfermedad crónica y rara y sus síntomas se caracterizan por debilidad muscular, fatiga intensa y dolores musculares y articulares, entre otros síntomas. El propósito de este artículo es entender que las narrativas sobre la enfermedad se difunden por asociaciones de pacientes con PostSíndrome de polio y sus usos en medios digitales. Analizaremos dos organizaciones de pacientes, una de Brasil y otra de España, a saber: la Asociación Brasileña de Síndrome de Pospolio (Abraspp), fundada en 2004 en São Paulo, Brasil, y la Asociación Afectados de Polio

\footnotetext{
${ }^{1}$ Doutoranda pela Casa de Oswaldo Cruz, Fundação Oswaldo Cruz (Fiocruz), do Programa em História das Ciências e da Saúde (PPGHCS). Técnica em Assuntos Educacionais no Instituto de Estudos em Saúde Coletiva (IESC), da Universidade Federal do Rio de Janeiro, UFRJ. E-mail: daniellesouzafialgo@gmail.com. Orcid: https://orcid.org/0000.003.0594.5778.
} 
y Post-polio Syndrome, fundada en 2000 en Madrid, España. En nuestro estudio cualitativo, analizamos las páginas institucionales de ambas asociaciones que se encuentran en medios digitales con acceso abierto. Tanto Abraspp como Asociación Afectados de Polio y Sindrome Post-polio señalan como rol principal de su asociación el carácter de difundir información sobre el síndrome, tomando para el colectivo la co-elaboración de políticas inclusivas y la defensa de los derechos de las personas con discapacidad. Se observó que en las fuentes digitales analizadas de las asociaciones, la SPP no es classificada como un síndrome raro.

Palabras clave: Síndrome Post-Polio; Asociaciones de enfermos; medios digitales, activismo, enfermedad rara.

\title{
POSTPOLIO SYNDROME NARRATIVES IN BRAZILIAN AND SPANISH PATIENT ASSOCIATIONS IN DIGITAL MEDIA
}

\begin{abstract}
Postpoliomyelitis syndrome (PPS) is a condition that affects people who have had polio many years after the acute illness. It is considered a chronic and rare disease and its symptoms are characterized by muscle weakness, intense fatigue and muscle, joint pain, among others symptoms. The purpose of this article is to understand that narratives about the disease are disseminated by associations of patients with Post-polio Syndrome and its uses in digital media. We will analyze two patient organizations, one from Brazil and one from Spain, namely: the Brazilian Post-polio Syndrome Association (Abraspp), founded in 2004 in São Paulo, Brazil, and the Asociación Afectados de Polio y Post-polio Syndrome, founded in 2000 in Madrid, Spain. Our qualitative study, we analyzed the institutional pages of both associations that are on digital media with open access. Both ABRASPP and Asociación Afectados de Polio $y$ Sindrome Post-polio signal as the main role of their association the character of disseminators of information about the syndrome, taking for the collective the co-elaboration of inclusive policies and defense of the rights of people with disabilities. It was observed that in the digital sources analyzed by the associations, PPS is not considered as a rare syndrome.
\end{abstract}

Keywords: Post-polio syndrome, Patient Associations; digital media, activism, rare disease.

\section{Apresentação}

O objetivo deste artigo é compreender que narrativas sobre a doença são divulgadas pelas associações de pacientes com Síndrome Pós-Pólio e seus usos nos meios digitais. Analisaremos duas organizações de pacientes, uma do Brasil e uma da Espanha, a saber: a Associação Brasileira de Síndrome Pós- poliomielite (Abraspp), fundada em 2004 em São Paulo, Brasil, e a Asociación Afectados de Polio y Síndrome Post-polio, fundada em 2000 em Madrid, Espanha. O tema de estudos se insere no campo da história das doenças, no qual buscamos entender as múltiplas dimensões que as abarcam esta doença crônica. Em nosso estudo qualitativo, analisamos as páginas institucionais de ambas associações que se encontram 
em suportes digitais com acesso aberto $^{2}$. Queremos compreender: que narrativas sobre a doença são publicadas em tais suportes? Quais são as lutas dos pacientes? Quais são as diferenças e semelhanças?

A Síndrome Pós-poliomielite (SPP) é uma patologia que acomete indivíduos que foram afetados pelo vírus da pólio muito anos antes, enfrentando novos sintomas físicos como fraqueza muscular, fadiga intensa e dores musculares e articulares. Segundo Quadros et al. (2010), a síndrome é uma desordem neurológica considerada dentro do capítulo dos efeitos tardios da poliomielite, caracterizado por fatigabilidade muscular anormal, podendo ocorrer também dores nas articulações. Esta manifestação ocorre em pessoas que tiveram poliomielite aguda e, após viver um período de estabilidade, enfrentam uma piora do seu estado físico ${ }^{3}$.

Em nossa pesquisa ${ }^{4}$, verificamos que muitos pacientes encontram dificuldades para obter o diagnóstico. Relatos de desconhecimento nosológico e social da doença são comuns. Apesar do reconhecimento oficial com o ingresso na Classificação Internacional de Doenças 10(CID 10), os indivíduos relatam desconhecimento dos próprios profissionais de saúde, de colegas de trabalho, amigos e familiares. Em virtude dos pacientes afetados não serem mais jovens, é comum que suas queixas relacionadas a fadiga, dor, e fraqueza sejam atribuídas à velhice. Inclusive, a morte dos pacientes e o não aparecimento de novos casos, contribui para que a síndrome pós-pólio seja uma doença de baixa prevalência (RODRIGUES-SANCHEZ \& GUERRA SANTOS: 2019).

A organização dos pacientes em associação nos remete ao movimento coletivo de mobilização no contexto da epidemia de Aids, no final da década de 80 e início dos anos 90, com o irromper da "voz do paciente"(HERZLICH,2004). Significa dizer que os estudos do campo da sociologia e da história se dedicaram ao domínio privado. Concomitante a tal período, diversas organizações compostas por pacientes e familiares foram estruturadas nas Américas e Europa para lutar por direitos à tratamento e acesso a medicamento. Podemos dizer que os

\footnotetext{
${ }^{2}$ A página da Abrassp encontra-e na plataforma do Facebook. Facebook é uma empresa americana que existe desde 2004, oferecendo serviços de comunicação interativa via uma plataforma eletrônica no qual o acesso é feito por meio de uma conta. Para se inscrever o indivíduo precisa ter um endereço de correio eletrônico e aceitar a política da empresa referente aos dados pessoais. Na plataforma podemos encontrar a classificação interna de " página" (pública), “perfil” ou "grupo", que podem ser "aberto" ou” fechado". A página da Asociación Afectados de Polio y Síndrome Post-polio é um fomato digital que possui postagem aberta e também espaço para login e senha para pessoas vinculadas à associação mediante pagamento de mensalidade. Seu formato aberto inclui "abas" com tópicos com assuntos ligados ao universo do paciente com SPP.

${ }^{3}$ A literatura médica sobre o tema assinala 15 ou mais anos, ver Bule Oliveira \& Mayanard (2002).

${ }^{4}$ Este artigo se insere nos estudos e nas pesquisas desenvolvidas durante o Programa de Doutorado sanduíche financiados pela Capes (Coordenação de Aperfeiçoamento de Pessoal de Nível Superior), do Programa CapesPrInt Fiocruz (2019-2020), no período de janeiro a novembro de 2020 com o professor Doutor Juan Atónio Rodrigues Sanchez, do departamento de História das Ciências da Faculdade de Medicina, da Universidade de Salamanca (Usal).
} 
modelos associativos foram variados, constituído por meio de parcerias com instituições de pesquisa em saúde, laboratórios e até mesmo organizações independentes ${ }^{5}$.

No bojo das transformações organizativas verificou-se o fenômeno do "paciente especialista" (EPSTEIN, 2007; PEREIRA NETO, 2015), sobretudo, com a virada tecnológica da web 2.0 que autorizou aos indivíduos acesso e maior circulação de informações, bem como interação entre pacientes por meio digital. É por meio de plataformas como o Facebook ou páginas eletrônicas que as associações e grupos de pessoas que sofrem com doenças, muitas vezes desassistidas e invisibilizadas, vem se organizado como no caso dos pacientes com Síndrome Pós-poliomielite. Nas postagens abaixo, podemos ler:

\begin{tabular}{|lll|}
\hline Maravilha! Que lindo! ALGUNS & Nuestra historia se repite. ¿Sabes por qué? No te \\
POUCOS!!! FAZENDO PARA TODOS??? & limites a mirar, actua. ${ }^{7}$ \\
Associação & Brasileira de Síndrome Pós- & Asociación Afectados de Polio y Síndrome Post- \\
poliomielite & polio
\end{tabular}

"Alguns poucos fazendo para todos" e "não se limite a ver, atue" são frases que narram os desafios que enfrentam estas associações. É no ciberespaço (PLANELLS, 2008) que estes pacientes podem recrutar indivíduos para atuar, lutar por direitos e evidenciar suas críticas ao próprio movimento como podemos verificar no início deste artigo. Neste estudo, verificamos que as duas associações pesquisadas - Abraspp e Asociación Afectados de Polio y Syndrome Pos polio - foram fundadas no mesmo período histórico, com uma diferença de 4 anos de uma para outra. Ambas associações se inserem no ciberespaço de forma singular. Buscaremos evidenciar esta singularidade ao longo deste texto, após algumas considerações sobre aspectos nosológicos ${ }^{8}$ da SPP como doença rara.

\section{Pólio como doença epidêmica e Síndrome Pós-Pólio como doença de baixa prevalência}

Podemos localizar uma mudança significativa na década de 1950, na qual os Estados Unidos tiveram uma de suas maiores epidemias, contribuindo para pressionar uma política sanitária e pesquisas para imunização. A historiografia assinala que foi partir de tal período que

\footnotetext{
${ }^{5}$ Sobre este assunto ver o artigo de CALLON, M. e RABEHARISOA,V.(2003)

${ }^{6}$ Comentário na página da Associação Brasileira de Síndrme Pós-polio ( Abraspp), públicado em 18 de abril de 2013, capturado em https://www.facebook.com/abraspp.org.br/posts/629146557112600. Caixas altas do texto da própria página do Fecebook.

${ }^{7}$ Postagem da Asociación Afectados de Polio y Síndrome Post-polio, capturado em : ado em 17/11/2020.

${ }^{8}$ Nosologia designa a parte da medicina que descreve, diferencia e classifica as doenças.
} 
se criaram tecnologias que possibilitaram seu controle e erradicação (CUETO et al.,2010,P.162) a saber: a vacina Salk e Sabin - com o desenvolvimento das técnicas de laboratório para diagnóstico da doença, a definição do conceito e implementação de procedimentos de vigilância epidemiológica e a formação de estratégias de vacinação.

Contudo, o investimento em vacinas como a Salk e a Sabin teve inúmeras controvérsias, seja pelos custos para os governos, seja pela dificuldade de vacinar em massa a população e até mesmo as disputas científicas envolvidas. Mesmo durante o período da comprovada efetividade da imunização, muitas pessoas foram infectadas com o vírus da pólio. Somente quando a poliomielite tornou-se doença "candidata" à erradicação (EVANS,1985), tal qual a varíola, as vacinações em massa trouxeram resultados positivos. O Brasil recebeu a Certificação da Erradicação da Poliomielite pela Organização Mundial da Saúde (OMS) em 1994, assim como as Américas (NASCIMENTO: 2010, P.114).

$\mathrm{Na}$ Europa a erradicação do vírus da pólio foi certificada pela Organização Mundial de Saúde em junho de $2002^{9}$.Tanto Portugal como Espanha tem imprecisão no número de infecções ${ }^{10}$ durante os anos de epidemia. Foram dois países que viveram sob regimes ditatoriais, logo após a segunda guerra mundial ${ }^{11}$, e que tinham tradição confessional católica. Segundo Rodriguez Sanchez (2010) “dois elementos determinantes da sua resistência a conceber a saúde e assistência em termos de direitos, mais do que beneficência e, sobretudo, condicionantes do valor concedido à doença e à morte" (2010, p.194). A diminuição efetiva dos casos nas regiões espanholas foi em consequência da primeira campanha oficial gratuita de vacinação oral em 1963-1964 (Rodriguez- Sanchez, 2010, p.196).

Na segunda metade da década de 1970, muitas pessoas que tinham sequelas da pólio levaram para os consultórios médicos suas queixas de sintomas dolorosos, fadiga e fraquezas muscular anunciando novos desafios para os profissionais de saúde. Nos EUA, o enquadramento destes sintomas ficou conhecido como Síndrome Pós-Polio, que foi nominado

\footnotetext{
${ }^{9}$ Ver informação no texto "Maintaining polio-free status of European Region as part of the global polio Endgame Strategy" do site da Organização Mundial de Saúde, capturado do : https://www.euro.who.int/en/healthtopics/communicable-diseases/poliomyelitis/maintaining-polio-free-status-of-european-region-as-part-ofthe-global-polio-endgame-strategy, acesso em 23 de novembro de 2020.

${ }^{10}$ Sobre este assunto ver o artigo de Inez Guerra Santos “ A poliomielite em Portugal: O refúgio da Paralisia Infantil”" e de J In: Nascimento, D. (Org.).A História da Poliomielite, Rio de Janeiro: Garamond, 2010.

11 Os autores também notam que apesar da pólio ser uma doença de notificação obrigatória, os dados epidemiológicos das pessoas que contraíram poliomielite durante os anos de epidemia que afetou as Américas e a Europa não são precisos em Espanha e em Portugal. Dentro das representações da doença percebemos que é atribuído ao periodo de Guerra Fria a negação de epidemias na Europa. Estas representações também são observadas no Brasil como na Argentina ocorreu o mesmo durante os períodos de ditadura. A poliomielite trazia medo para a população por ser, em alguns casos, uma doença letal ou trazer sequelas para o resto da vida.
} 
na década de $1980^{12}$. No entanto, passaram três décadas até o ingresso na Classificação Internacional de Doenças (CID), em 2010, com o código de G-14.

Segundo Nascimento (2010), as pessoas que tiveram pólio durante anos foram estimuladas a superar as limitações físicas para construir sua vida profissional e familiar. Muitas passaram por inúmeras cirurgias e fisioterapia reabilitadora intensa. Tal reabilitação dos membros afetados demandou um uso excessivo da musculatura, denominado pelos médicos “overuse”. Segundo Quadros et al.(2010), o overuse crônico dos músculos pode resultar no desenvolvimento de nova fraqueza, que por sua vez pode levar ao desuso musculoesquelético, gerando fraqueza maior, atrofias, diminuição da resistência e ganho de peso. Dentro deste novo quadro patológico, muitas pessoas começam a cair e a sentir que não conseguem mais fazer suas atividades com o mesmo desempenho. De fato, devido à sintomatologia apresentada, o protocolo de tratamento estabelece que todas as atividades físicas e laborais devem incluir intervalos de repouso e diminuir o ritmo nas tarefas cotidianas.

Dentro de um cenário de uma doença de baixa prevalência a SPP foi enquadrada como doença rara (RODRIGUES-SANCHEZ, 2019; TESTA, 2018). Segundo consulta a informações institucionais, a doença foi registrada antes de 2005 no Portal de doenças raras e medicamentos órfãos, denominado Orphanet ${ }^{13}$. A baixa prevalência é explicada pelos pesquisadores em parte pela quantidade de pessoas que apresentam este novo quadro de sintomas - cerca de $80 \%$ dos indivíduos afetados pela poliomielite podem desenvolver a SPP (RODRIGUESSANCHEZ,2012). Além disso, o número de pacientes é reduzido a cada ano em função das mortes e da erradicação da pólio no mundo.

As patologias raras compõem um universo de doenças que podem ser divididas basicamente entre dois grupos: as de origem genética (cerca de $80 \%$ ), que podem matar nos primeiros anos de vida, e as crônico-degenerativas, que podem ser causadas por algum patógeno agente de uma infecção. Segundo Juan Coca (2019) são doenças de baixa prevalência e podese dizer que englobam uma pluralidade complexa que abarca uma quantidade de mais de 6.000 patologias (COCA, 2019, pág.11). Trata-se de doenças de difícil diagnóstico e que traz um componente de exclusão preocupante de nível social e biomédico para pessoas e famílias

\footnotetext{
${ }^{12}$ Morinos Dalakas assinala que foi em 1985 a primeira apresentação sobre o tema da síndrome Pós-pólio a comunidade dos neurologistas na American Academy of Neurology, ver Dalakas(1985).

${ }^{13}$ Orphanet é um web site europeu que oferece informações sobre medicamentos órfão e doenças raras. Ver plataforma Orphanet sobre a síndrome Pós-poliohttps://www.orpha.net/consor/cgibin/Disease_Search.php?lng=EN\&data_id=3388\&Disease_Disease_Search diseaseGroup=post-poliosyndrome-

\&Disease_Disease_Search diseaseType=Pat\&Disease(s)/group\%20of\%20diseases=Postpoliomyelitissyndrome\&title=Postpoliomyelitis\%20syndrome\&search=Disease_Search_Simple, acesso dia 22 de setembro de 2020 .
} 
afetadas (IDEM, pág.12). O autor assinala que as doenças raras podem ter componentes epigenéticos ${ }^{14}$ e ambientais. Sobretudo, neste último, pode-se inferir que, a princípio, tal componente pode estar vinculado à desigualdade social, pois as diferenças sociais expõem os indivíduos desigualmente a substâncias potencialmente patológicas. Desta forma, pessoas expostas a substâncias tóxicas, por exemplo, podem desenvolver tumores e provocar doenças degenerativas.

Em pesquisa qualitativa realizada na Espanha (COCA \& VALERO MATAS, 2019) foi observado que a questão do diagnóstico é crucial para pacientes com doenças raras (DR) e seus familiares, pois é vital para estabelecer a identidade biomédica. A partir do diagnóstico, existe uma ressignificação da existência baseada no caráter de "raridade" e, neste sentido, muitas pessoas podem se sentir "raras", depreciadas ou excluídas. No estudo, constatou-se que a exclusão social das pessoas com DR possui uma relação intrínseca entre carência de informação sobre as patologias e exclusão médica. Por outro lado, notou-se que dentro do universo das pessoas e famílias afetadas com DR há mais pró atividade na busca de informação e tratamento, provocando transformações dentro do contexto das relações médicas. Os autores assinalam a necessidade de educação social para ajudar os pacientes. A pesquisa de Coca \& Valero Matas nos faz pensar sobre como a SPP afeta os pacientes e de que forma o conhecimento pode ajudar a diminuir a exclusão de pessoas com doenças raras crônicas.

Edelvis Testa (2014) sugere que o que ocorre com a SPP tem uma relação com esta baixa prevalência epidemiológica. Segundo a autora, "considerada dentro do grupo de “enfermidades raras" parece que o número de indivíduos não é suficiente para justificar investimentos nas pesquisas sobre o tema.” (EDELVIS TESTA, 2014, p.244). Coca e Rodrigues-Sanchez (2019), concordam com este ponto de vista sobre o pouco investimento em relação à doença de baixa prevalência como a SPP. Sobre os dados epidemiológicos, Testa (2014) assinala que a historiografia da poliomielite nos recorda que não só os números fazem com que a enfermidade seja reconhecida como um problema social e de agenda sanitária, mas da mesma forma produz uma pressão para respostas governamentais.

Embora a baixa prevalência possa ser relacionada com o desconhecimento, não podemos esquecer que as pessoas que tiveram pólio passaram por um desafio constante para obter diagnóstico e tratamento para a SPP. Os sintomas de dor e fraqueza, bem como de atrofia muscular, muitas vezes impossibilitam seus pacientes de exercer tarefas antes corriqueiras, ou

\footnotetext{
${ }^{14}$ Segundo Sanchez Freire et al. (2013) : "La epigenética hace referencia, en un sentido amplio, al estudio de todos aquellos factores no genéticos que intervienen en la determinación de la ontogenia. “ - ou seja, fatores que que atuam no desenvolvimento de um indivíduo desde sus concepção até a maturidade.
} 
mesmo continuar as atividades laborais e cotidianas. É comum entre família, amigos e colegas de trabalho o julgamento de que a pessoa está sendo "preguiçosa", ou que "não quer trabalhar". Em alguns casos, as pessoas que estão sofrendo com estes novos sintomas buscam obter licenças para se afastar do trabalho ou aposentadoria.

\section{As organizações de pacientes, associativismo e os meios digitais}

Sabemos que o reconhecimento da Síndrome Pós-pólio deve-se sobretudo as pessoas afetadas (DALAKAS, 1995; RODRIGUEZ-SANCHEZ, 2012b) que se organizaram e buscaram aliados do campo da medicina para a constatação de que sua doença existe. Alguns processos contemporâneos que envolvem diagnóstico, tratamento e demanda por medicamentos e tomada de decisão revelam um empoderamento dos pacientes e reflete o papel ativo em relação as demandas que cercam saúde e doença. Dalakas (1995), um dos médicos responsáveis pelo enquadramento da SPP nos EUA, observou que a persistência dos pacientes em mostrar que os sintomas vividos não eram uma entidade antiga ou descrita permitiu a nomeação e a classificação médica.

Este papel do "paciente ativo", conhecedor da sua doença, foi verificado nos estudos sobre o movimento de pacientes da Síndrome Pós-pólio na Espanha (RODRIGUEZSANCHEZ, 2012b). A arena histórica de transformações em relação a este papel, nos remete aos anos de 1960, sobretudo, com o surgimento de diversos movimentos contestatórios, como o feminismo - atento as relações de poder e a construção social do corpo - modificou o olhar sobre o "modelo de incapacidade". Tal mudança está relacionada a referências teóricas norteamericanas que, segundo o autor, transitaram de um "modelo reabilitador", no qual a incapacidade é um problema individual, para um "modelo de incapacidade social", que entende a importância de perceber a circunstância que tornou o indivíduo incapaz. Nesta compreensão, a experiência pessoal da doença é uma informação relevante e a relação com profissionais biomédicos é criticada em nome de uma relação mais horizontal, na qual o paciente tem voz própria (IDEM, p.106-107).

O ativismo espanhol dos pacientes com síndrome pós-pólio para Rodrigues- Sánchez (2012b) possui contribuições importantes dos movimentos associativos ligados à igreja católica no período da ditadura franquista. A ditadura implantou uma política repressiva às associações civis, permitindo apenas as católicas. Desta forma, estas organizações, além de promover cuidados aos considerados inválidos, buscavam evangelizar e promover uma normalização social mediante campanhas de visibilidade (RODRIGUEZ-SANCHEZ, 2012b). As 
fraternidades católicas promoveram um ideário, valores e uma socialização para pessoas afetadas pela pólio (RODRIGUEZ-SANCHEZ, 2012a). Podemos destacar inclusive o papel destas organizações para formar líderes, fundamental no engajamento e ativismo dos pacientes com Síndrome Pós-pólio.

A semelhança com Herzlich (2004), acreditamos que os movimentos associativos de pacientes experimentaram uma grande renovação durante a epidemia de Aids, promovendo uma mudança no modelo de luta contra a doença. No Brasil, Nascimento (2005) chama atenção para o fato que à medida que a contaminação da Aids se espalhava surgiram organizações de pacientes. Observa-se também que, no final da década de 80 , tais organizações uniram o ativismo e luta pela democracia (LIMA, 2019). Sabe-se que esta renovação do ativismo atingiu também pacientes com câncer e doenças raras e, em todas as associações "os pacientes se convertiam em agentes ativos na busca de sua saúde e partícipe das decisões políticas, econômicas e, inclusive, as de controle de investigação e colaboração nos ensaios clínicos" (Rodriguez-Sanchez, 2012b, p.112). ${ }^{15}$

$\mathrm{O}$ advento da internet e o acesso a rede, sobretudo, com as mudanças interativas incrementou diversas formas de ativismos, voltados para política para pacientes, que alguns autores denominam de technoativismo ${ }^{16}$. O que queremos sublinhar aqui é a qualidade diferenciada deste engajamento que utiliza tanto dispositivos quanto suportes eletrônicos como "aliados" - que são ao mesmo tempo suporte para circular informação e meio de luta. Neste ponto, podemos relacionar com as reflexões sobre o conceito de pacientes especialista e, especialista pela experiência ${ }^{17}$, e suas estratégias para dar visibilidade às doenças crônicas. $\mathrm{O}$ conhecimento dos pacientes sobre a Síndrome Pos-Pólio - de como a doença os afeta e como se deve $\operatorname{tratar}^{18}$ - são postados pelas associações de pacientes e são temas também dos encontros e reuniões. Apesar de sabermos que nem todos possuem acesso da mesma forma aos

\footnotetext{
${ }^{15}$ Livre tradução.

${ }^{16}$ Ver a discussão sobre as caracteristicas do ativismo digital tanto político, quanto de pacientes, problematizados por Callén et al. Technoativismo y politica de la información. In: SÁBADA, Igor y GORDO, Angel (coords) Cultura Digital y movimientos sociales. Madrid: Catarata, 2008. pág.267-297

${ }^{17}$ Estes conceitos relacionam-se com o desenvolvimento e apropriação de conhecimentos dos pacientes sobre a sua própria doença e que são suportes importantes para comunidade médico-científica elaborar terapêuticas. O coletivo dos familiares-pacientes com doenças raras constituem um caso exemplar para pensar tanto a produção quanto a circulação de conhecimento. Sobre este assunto ver autores Callon \& Rabeharisoa(2003), Epstein (2004), Pereira Neto (2015), Barbosa \& Portugal (2017).

${ }^{18}$ No caso da Asociación Afectados de Polio y Sindrome Post-polio divulgam na barra "Recomendaciones", ver este assunto em http://www.postpolioinfor.org/recomendaciones/, acessado em 17/11/2020.
} 
dispositivos eletrônicos e conexão de internet ${ }^{19}$, consideramos que estes conceitos nos ajudam a pensar os engajamentos dos pacientes com SPP em torno de associações.

Como assinalamos no início do artigo, as primeiras organizações de pacientes do Brasil e Espanha tem sua fundação em datas muito próximas, como podemos ler abaixo no texto das postagens:

A ABRASPP - Associação Brasileira de Síndrome Pós-Poliomielite foi criada em 21 de fevereiro de 2004, como uma organização sem fins lucrativos, por pacientes, familiares, médicos e profissionais de saúde como uma alternativa de apoio aos portadores de Síndrome Pós-Poliomielite (SPP) e para a difusão dos seus efeitos sobre os indivíduos ${ }^{20}$

Nuestra Asociación nace en febrero del 2000, de las necesidades especificas del colectivo (tratamiento médico, laborales, eliminación de barreras arquitectónicas, ayudas técnicas, etc.) y del conocimiento por Internet, que los síntomas que padecíamos tienen nombre y apellidos SÍNDROME POSTPOLIO - SPP. ${ }^{21}$

No texto da página da Asociación Afectados de Polio y Síndrome Post-polio, da Espanha, destacados no início deste tópico, fica aventado a estruturação de conteúdos digitais para alimentar os pacientes de informação acerca de suas demandas desde seu "nascimento", ou seja, desde a fundação da associação. Inclusive, a página informa que existe entre os membros um trabalho de recompilação e difusão de documentos sobre a SPP desde de 1998, bem como, reuniões desde $2011^{22}$. De maneira semelhante, podemos ler sobre ABRASPP:

Desde seu início, a Abraspp desenvolve duas atividades fundamentais para a consecução de seus objetivos, assim como a difusão de seus propósitos, quais seja:

1) Reuniões periódicas, abertas a todos interessados, onde são apresentadas informações atualizadas, pesquisas e avanças sobre a patologia, assim como questões referentes à associação.

2) Criação e manutenção do site eletrônico da Associação. Espaço voltado para difusão de informações, notícias, avanços e atualidades sobre a SPP e atividades da Associação. Endereço: www.abraspp.org.br ${ }^{23}$ (LIMA, S. IN: NASCIMENTO (org.)2010, p.297)

\footnotetext{
${ }^{19}$ Com "meios digitais" queremos dizer que são tanto os dispositivos (computador, tablet, smart phone androide ou IOS, notebook, etc.) quanto a rede de wi-fi ou outra forma de conexão ao sistema de internet.

${ }^{20}$ Ver a postagem da Abraspp no Facebook publicado entre dia tal e tal de 18/03/2013, Capturado em 30/11/2020.

${ }^{21}$ Negrito nosso, texto da página da Asociación Afectados de Polio y Síndrome Post-polio, capturado em $30 / 11 / 2020$.

${ }^{22}$ Ver estas informações do link: http://www.postpolioinfor.org/quienes-somos/ acesso em: 18/11/2020.

${ }^{23}$ Ao clicar no endereço eletrônico somos redirecionados para uma página do Instituto Giorgio Nicoli, pois a página original não está mais ativa. Tal página é mais antiga do que a estruturada no Facebook, que data de 2012.
} 
Um dos contrastes que podemos perceber entre as duas associações diz respeito a narrativa dos coletivos envolvidos em sua própria organização. Podemos ler (ver o início do tópico 3) que na Abraspp a sua fundação inclui: pacientes, amigos e profissionais de saúde. $\mathrm{O}$ coletivo de - médicos, fisioterapeutas, educadores físicos - são da Universidade Federal de São Paulo (Unifesp). Inclusive, apesar ceticismo sobre a síndrome ${ }^{24}$, foi o Setor de Investigação de Doenças Neuromusculares desta universidade responsável pelo atendimento das demandas das pessoas que buscavam apoio para o reconhecimento da Síndrome Pós-pólio e alívio terapêutico dos sintomas desde 2002. Por sua vez, a Asociación Afectados de Polio y Síndrome Post-polio destaca em sua página na barra "Quiénes Somos?":

Muchos de los miembros de esta Asociación, llevamos trabajando en la difusión y recopilación de información sobre el SÍNDROME POST-POLIO - SPP desde Noviembre de 1998.

También reclamamos para los afectados de POLIO y SÍNDROME POSTPOLIO, que puedan ejercer libremente sus derechos fundamentales, recogidos en la Constitución Española, la Declaración Universal de Derechos Humanos, y cualquier carta de derechos futura que ampare a las personas con Discapacidad y mejore su calidad de vida.

La Asociación no tiene ánimo de lucro, sus cargos no son retribuidos, no recibe subvenciones y desarrolla su trabajo con absoluta independencia económica y política.

En general las personas afectadas de poliomielitis, hemos luchado mucho, en tiempos muy difíciles, por conseguir una vida normalizada. Me atrevo a decir, que somos pioneros en la lucha por los derechos de los Discapacitados en este país. ${ }^{25}$ (texto capturado http://www.postpolioinfor.org/quienes-somos/ acessado em 17/11/2020.)

A associação espanhola ressalta "absoluta independência econômica e política" em sua narrativa e, inclusive, não vemos uma descrição de um vínculo com uma instituição universitária como no caso da associação brasileira Abraspp. Em seus argumentos, tal associação espanhola apoia-se na legalidade e na defesa de direitos dos pacientes, assinalando o passado de luta por direitos das pessoas deficientes ${ }^{26}$.

Neste sentido, o engajamento político aparece nas duas associações de pacientes. $\mathrm{Na}$ associação espanhola, Asociación Afectados de Polio y Sindrome Post-polio, lemos em suas postagens que são alvos de engajamento os direitos das pessoas com deficiência ${ }^{27}$, seja referente

\footnotetext{
${ }^{24}$ Ceticismo assinalado por uma paciente que foi diretora da Abraspp em seu capítulo "Abraspp: uma (re)ação brasileira" Ver Lima, Solane(2010)

${ }^{25}$ Negritos e destaques no texto pertencem ao texto da associação. Trecho capturado da página: http://www.postpolioinfor.org/quienes-somos/ acessado em 17/11/2020.

26 Traduzimos o termo espanhol "discapacidad" pelo termo "deficiente" utilizados no Brasil. Porém, sabemos que são termos que estão ligados à luta dos movimentos sociais por direitos e que estão presentes disputas discursivas e simbólicas.

${ }^{27}$ Livre tradução de "lucha por derechos de las personas con discapacidad".
} 
a medidas inclusivas, seja relativa à aposentadoria antecipada ${ }^{28}$. Foi observado que as estratégias de luta dos movimentos associativos de pacientes com síndrome pós-pólio na Espanha percorreram também a atuação dos partidos políticos e seus parlamentares ((RODRÍGUEZ-SÁNCHEZ, 2012a). A democracia permitiu que as associações utilizassem este recurso para pressionar o governo para ter suas reivindicações atendidas: reconhecimento da doença, apoio para tratamentos e auxílios de seguridade social no caso de incapacidade.

Já no Brasil, a luta pelo direito das pessoas com deficiência ganhou uma materialidade com a Constituição de 1988 que, por sua vez, marcou um novo capítulo na democracia brasileira. Segundo Maior (2018), na segunda metade da década de 1990, foi criada " $a$ Secretaria dos Direitos de Cidadania, no âmbito do Ministério da Justiça, após intensa negociação do movimento social $e$, internamente, nas instâncias governamentais, a Coordenadoria Nacional para a Política de Integração da Pessoa Portadora de Deficiência" (MAIOR, 2018, p.107). Um dos pontos importantes foi que o novo lócus institucional em 1986 muda o referencial: deixando a assistência social para vincular-se aos direitos humanos.

Na Abraspp verificamos que, um dos seus representantes e fundadores, já tinha uma trajetória de luta e militância em relação à defenda os direitos das pessoas com deficiência e que o levou a ser presidente do Conselho Municipal da Pessoa com Deficiência de São Paulo e também ser assessor para Inclusão da União de Vereadores do Estado de São Paulo ${ }^{29}$. Neste sentido, podemos inferir que da mesma forma que na organização espanhola, a organização brasileira contou com o aporte de um passado histórico de luta de seus participantes.

Em suas postagens na plataforma facebook, a Abraspp destaca a entrada no CID 10, fato este que é um importante marco para as pessoas que apresentam os sintomas da SPP. Podemos perceber na narrativa da postagem que houve ações organizadas dos pacientes com os aliados da Unifesp atuando com essa perspectiva de reconhecimento oficial da doença, podemos ler abaixo:

Brasil consegue incluir Síndrome Pós-Polio no CID

A batalha para incluir a síndrome no CID começou em 2004, quando Acary e pacientes, reunidos na Associação Brasileira da Síndrome Pós-Poliomielite (Abraspp), conseguiram sensibilizar autoridades da Saúde e o representante brasileiro no comitê internacional que regulamenta o CID, professor Rui Laurenti, no sentido de encaminhar ao organismo uma proposta de inclusão da SPP. http://www.saudeemmovimento.com.br/.../noticia frame.asp... Fonte: Assessoria de Comunicação da Unifesp. Publicado em: 18/12/2008 ${ }^{30}$

\footnotetext{
${ }^{28}$ Sobre este assunto ver documento de resposta do Congresso Espanhol: http://www.postpolioinfor.org/pdf/IMGgg.pdf

${ }^{29}$ Ver a postagem do dia 26 de janeiro de 2013 capturada do Facebook:

https://www.facebook.com/Abraspp.org.br/posts/584686338225289, acessada em 17 de novembro de 2020.

${ }^{30}$ Postagem do Facebook da Abraspp capturado de:
} 
Tal notícia na postagem assinala uma conquista importante para os pacientes brasileiros e de outros países pois o ingresso na Classificação Internacional de Doenças 10 (CID10) da Organização Mundial de Saúde estabelece um reconhecimento médico oficial para os pacientes - ou seja, uma base institucional e científica que permitem lutarem por mais direitos. Apesar deste reconhecimento oficial, é comum pacientes relatarem desconhecimento da síndrome tanto no meio familiar, laboral e até mesmo sanitário. Na associação espanhola vemos postagens semelhantes de não reconhecimento das autoridades públicas :

\begin{abstract}
En España llevamos 20 años de retraso en relación con otros países, que cuentan con investigaciones, comités de expertos, clínicas de tratamiento, realización de congresos, etc. En España por parte de organismos encargados de la valoración de discapacidades, se niega la existencia del síndrome postpolio. Nosotros nos hacemos esta pregunta: ¿Por qué? (postagem do site: http://www.postpolioinfor.org/quienes-Somos/ acessado dia 11/11/2020)
\end{abstract}

Ao questionamento da Asociación Afectados de Polio y Sindrome Post-polio, acima, podemos refletir que um dos motivos na demora do reconhecimento da SPP estaria relacionado à pressão pela busca do certificado de erradicação da poliomielite no continente Europeu - pois as sequelas da pólio e a síndrome mostravam o quanto a doença ainda estava presente, segundo Sanchez (2012). Mais uma vez, o ativismo dos pacientes foi importante para sensibilizar a população, utilizando-se dos periódicos e abrindo espaço na televisão. Por outro lado, muitos percebiam que a demora em reconhecer a gravidade das sequelas e a prestação de auxílio aos pacientes poderia ser uma estratégia mórbida do governo espanhol, já que com o passar dos anos o número de doentes diminuiria naturalmente (RODRIGUEZ-SANCHEZ, 2012, p.111).

Um assunto que é destacado na página do facebook da Abraspp diz respeito a inúmeras postagens de uma pesquisa de medicamento para SPP com pacientes. Em contraste com a página da associação espanhola, que não possui nenhuma postagem deste tipo (até o presente momento) chama a atenção a divulgação de tal pesquisa feita pela Abraspp. Os textos postados incluem cadastro e guardam relação com os médicos do Setor de Investigação de Doenças Neuromusculares da Universidade Federal de São Paulo (Unifesp), como podemos ler abaixo:

Notícias do estudo do remédio, eu M.A., estive na Neuromuscular hoje pela manhã (por sinal LOTADA), falei com o Dr. Abrahão Presidente da Abraspp para tentar entender como esta indo o projeto?

Como esta sendo feito ?

Já ligaram para muitos inscritos mas ainda faltam ligações, aos que se inscreveram, localizar o cadastro com o histórico de conclusão de diagnóstico em SPP , ser paciente da Neuromuscular, depois de verificado alguns itens, como andar... eles pedem alguns exames, e depois de colher esses resultados 
eles pedem mais alguns exames até chegar no ponto necessário do estudo, como é multidisciplinar são vários os pontos a serem vistos até que chegue ao ponto de estar coerente com o projeto.

Somos cadastrados na neuromuscular mais ou menos 1500 pacientes todos gostariam de participar mas temos que respeitar o que os Mestres Dr Acary e Dr. Abrahão estabelecer como regra e nem eles mesmos podem dizer quem pode ou não participar sem antes passar por todas as etapas.

Devemos acreditar que antes de qualquer coisa, o benefício será colhido para os que estiverem dentro do estabelecido no estudo, nem todos tomam os mesmos remédios HOJE, pode ter até o mesmo nome mas com manipulações diferentes a cada caso(somos únicos) e é por isso que não devemos tomar ou informar nomes de remédios para ninguém o respeito pelo seu corpo começa por vc. Boa sorte a todos nós. (Postagem realizada em 11 de junho de 2013, acessado em 11 de novembro de 2020)

A postagem acima assinala o desafio de se estabelecer uma pesquisa de medicamento de acordo com os protocolos médicos-científicos e a demanda dos pacientes por algo que traga alívio e cura para sua doença - no caso da SPP, um alívio para as dores e a degeneração do sistema motor. No entanto, o que queremos destacar é o vínculo estreito entre pacientes e a instituição universitária, em aspectos relacionados a colaboração dos pacientes com a construção de uma possibilidade terapêutica farmacológica. O texto da publicação possibilita refletir como as associações apoiam-se no saber especializado e se assentam nas suas redes (pacientes) para ampliar a base de pesquisa e conhecimento de instituições universitárias como a Unifesp. Neste sentido, também verificamos que na Asociación Afectados de Polio y Sindrome Post-polio estes conteúdos do saber especializado. A página on-line traz na barra “congresos y jornadas” informações sobre eventos médico-científicos sobre a síndrome em toda a Europa, classificado por data e título, e pequenos resumos e destaques de assuntos, artigos, ao acessar seus conteúdos.

\section{Considerações finais}

A novidade do associativismo contemporâneo reside no ativismo, na visibilidade e nas alterações qualitativas que imprimem maior relevância social (EPSTEIN,2007). No bojo deste novo ativismo de pacientes, Callon e Rabeharisoa (2003) destacam os movimentos de interrelação entre grupos de especialistas - que inclui médicos, pesquisadores e profissionais de saúde de uma forma geral - e grupos de não-especialistas - formados por pacientes, familiares e amigos. Estes últimos exercem, segundo os autores, um papel transformador na compreensão da doença na história recente. Tais grupos são importantes no que tange ao direcionamento das pesquisas médicas, científicas, relacionadas tanto aos enquadramentos das enfermidades quanto 
ao seu tratamento. Neste sentido, vemos uma relação destas primeiras associações de pacientes a Associação Brasileira de Síndrome Pós-pólio e a Asociación Afectados de Polio y Sindrome Post-polio espanhola com este movimento de enquadramento sobre a sua doença.

Nos meios digitais observamos semelhanças nas narrativas das associações de nossa investigação. A Abraspp, na plataforma Facebook, destaca imagens, textos e publicações relativa tanto ao seu fazer institucional quanto a sua memória: fundadores (pacientes e profissionais de saúde), suas lutas políticas (inclusão no CID, direito à aposentadoria antecipada), eventos institucionais (como por exemplo encontros de pacientes e profissionais de saúde) e pesquisa de medicamentos. Tanto a Abraspp quanto a Asociación Afectados de Polio y Sindrome Post-polio sinalizam o caráter de divulgadoras de informações sobre a síndrome, tomando para o coletivo a co-elaboração de políticas inclusivas e defesa de direitos de pessoas com deficiência.

A associação espanhola enfatiza uma narrativa de luta apoiada na legalidade e cobrança ao poder público, bem como, de possibilidade de judicializar o governo espanhol para que o paciente possa ter seus direitos garantidos, neste ponto, não vemos correspondência nas postagens estudadas ${ }^{31}$. Algo particularmente intrigante é o fato de não ter nestas duas associações menção sobre a SPP como doença rara $^{32}$ - algo que verificamos em outros grupos de pacientes dos dois países. Neste sentido, consideramos um dado importante, visto que o enquadramento da síndrome pós-pólio como doença rara pode aportar um capital simbólico significativo para seus pacientes e sua luta.

\section{Referências bibliográficas}

BARBOSA, R. \& PORTUGAL, S. (2017). O Associativismo faz bem à saúde? O caso das doenças raras. Revista Ciência e Saúde Coletiva. Vol. 23 N.2 , 2018.

\&lng=es\&nrm=iso>. accedido en 29 nov. 2020.

BULE OLIVEIRA, A; MAYANARD, F. M (2002). Síndrome Pós-poliomielite: aspectos neurológicos. Rev. Neurociências, 10 (1):pp. 31-34.

CALLON, M.; RABEHARISOA, V. Research 'in the Wild' and the Shaping of New Social Identities. Technology in Society, v.25, issue 2, p. 193-204, 2003.

\footnotetext{
31 Em nossa pesquisa, observamos que as estratégias políticas são construídas em torno de representantes (deputados e vereadores, por exemplo). É possível afirmar em relação a Abraspp que grande parte de seu conteúdo ficou dividida entre a página institucional fora da plataforma Facebook, e que agora não está mais ativa. Por outo lado, a criação da associação G-14, como substituta e continuadora da luta da Abraspp, mobilizou os pacientes em torno desta instituição.

${ }^{32}$ Verificamos que a Abraspp organizou evento em conjunto com associações de doenças raras, ver postagem do dia: 12/04/2020 E 17/04/2020, ver o link:

https://www.facebook.com/Abraspp.org.br/photos/a.525083800852210/628845583809364, acesso em $11 / 11 / 2020$
} 
CALLÉN ET AL. Technoativismo y politica de la información. In: SÁBADA, Igor y GORDO, Angel (coords) Cultura Digital y movimientos sociales. Madrid: Catarata, 2008. pág.267-297

COCA, J. R. Enfermedades raras: contribuiciones a la investigación social y biomédica. Soria: Ceasga publishig, p.1-178, 2019.

COCA, J. R.; VALERO MATAS, J. A. Analisis cualitativo de la realidad social de personas y familias afectadas por enfermedades raras em España. In: COCA, J. R. (coord.) Enfermedades raras: contribuiciones a la investigación social y biomédica. Soria: Ceasga publishig, p. 21-74, 2019.

CUETO, M. et al. A erradicação da poliomielite na América Latina : Comparando Brasil, Peru. In: NASCIMENTO, D.R. (org.). A história da poliomielite. Rio de Janeiro, Garamond, 2010. p.257-290

DALAKAS, M. C. Post-polio Syndrome 12 year later. How it all Started. In :Annals of New York Academy of Sciences, New York Academy of Sciences, 1995. Disponível em: https://doi.org/10.1111/j.1749-6632.1995.tb27527.x. Acesso em: 01/12/2020.

EDELVIS TESTA, D. La poliomielitis y el «surgimiento» de la rehabilitación en Argentina: Un análisis sociohistórico. Apuntes, 45(83), p. 123-143, 2018. Disponível em: https://dx.doi.org/https://doi.org/10.21678/apuntes.83.919. Acesso em: 03/03/2018.

EDELVIS TESTA, D. Todavia estamos aqui! Sindrome pos-polio y activismo em la web. In: Clío \& Asociados. La historia enseñada. Enero-Junio 2018 (26) ISSN 2362-3063 (digital), pp. 138-149 Universidad Nacional del Litoral - Universidad Nacional de La Plata (Santa Fe/La Plata-Argentina).

EDELVIS TESTA, D. El Síndrome Pos-polio y sus anundamientos em el pasado. Intersticios: Revista Sociológica de Pensamiento Crítico, v. 8, p.233-248, 2006.

EPSTEIN, S. Patient groups and health movements. In: New Handbook of Science and Technology Studies. California: MIT Press. 2007.

EVANS, A. The eradication of communicable diseases: myth or reality?. American Journal of Epidemiology, v. 122, n. 2, p.199-207, 1985.

HERZLICH, C. "Saúde e doença no início do século XXI: entre a experiência privada e a esfera pública". Physis: Revista de Saúde Coletiva, v. 14, n. 2, 2004.

LIMA, A.C.T. O câncer gay e o orgulho gay: a experiência da Aids para o movimento LGBT da cidade do Rio de Janeiro (1986-1995). Dissertação de mestrado do Programa de Pós-Graduação em História das Ciências e da Saúde (PPGHCS), Casa de Oswaldo Cruz, Fiocruz, 2019.

LIMA, Solane. Abraspp: uma (re) ação brasileira. In: Nascimento, D. R. do (org.) A história da poliomielite. Rio de Janeiro, Garamond. 2010.

MAIOR, I. M. M. L. A política de inclusão da pessoa com deficiência como questão de direitos humanos. Revista Científica de Direitos Humanos. v.1, n.1. p. 105-131, nov. 2018.

NASCIMENTO, D. R. Do (2015). Poliomyelitis vaccination campaigns in Brazil resulting in the eradication of the disease (1961-1994). Hygiea Internationalis, 11(1), pp131-146

NASCIMENTO, D. R. (org.). A história da poliomielite. Rio de Janeiro: Garamond, 2010.

NASCIMENTO, D. R. (org.). A história do controle e da erradicação da poliomielite no Brasil. In: NASCIMENTO, D. R. (org.). A história da poliomielite. Rio de Janeiro: Garamond, 2010. p. 85-118.

QUADROS et.al. A Síndrome Pós-poliomielite (SPP) In: NASCIMENTO (org.).A história da poliomielite. Rio de Janeiro, Garamond. p.257-290, 2010.

PEREIRA NETO, André et al. O paciente informado e os saberes médicos: um estudo de etnografia virtual em comunidades de doentes no Facebook. História, Ciências, Saúde Manguinhos, Rio de Janeiro, v. 22, p. 1653-1671, dez. 2015. 
POSADA M., MARTÍN-ARRIBAS C., RAMÍREZ A., VILLAVERDE A. y ABAITUA, I. 2008. Enfermedades raras: Concepto, epidemiología y situación actual en España. Anales del Sistema Sanitario de Navarra, 31(Suppl. 2), 9-20.

PLANELLS, J. M. La política de los nombres en la cibersociedad. Dimenciones analíticas, políticas y sociales del concepto de ciberespacio. In: SÁBADA, I.; GORDO, A. (coords) Cultura Digital y movimientos sociales. Madrid: Catarata, 2008.

RODRÍGUEZ-SÁNCHEZ, J.A 2011. De la minusvalía al síndrome postpolio: diagnóstico médico y movimientos asociativos en la creación de una identidad polio/postpolio. In: PorrasGallo, M.I. et al. (eds.). Transmisión del conocimiento médico e internacionalización de las prácticas sanitarias: una reflexión histórica. Universidad de Castilla la Mancha, Ciudad Real, 147-151.

RODRÍGUEZ-SÁNCHEZ, J.A. La persona enferma como experta: los cambios sociosanitarios promovidos por el asociacionismo polio-postpolio en España. Revista Estudos do Século XX, n.12, p.105-124, 2012a.

RODRÍGUEZ-SÁNCHEZ, J.A. Las secuelas sociales de la polio: los inicios del movimento asociativo en España (1957-1975). Dynamis, 32(2), p. 391-414, 2012 b.

RODRÍGUEZ-SÁNCHEZ, J.A. BALLASTER, R., SANTOS, Ines G. El movimiento asociativo una perspectiva internacional, nacional y los casos de Madrid, Valencia y Castilla La Mancha. In: PORRAS Galo, N. et all (coord.). El Drama de la polio: un problema social y familiar en la España franquista. Madrid: Los libreros de Catarata, 2013.

RODRÍGUEZ-SÁNCHEZ, J.A.; GUERRA-SANTOS, I. Denial, oblivion and new fears: Poliomyelitis and the post-polio síndrome in the Spanish and Portuguese press (19952009). Hygiea Internationalis, 11(1), p.93-129, $2015 \mathrm{a}$.

RODRÍGUEZ-SÁNCHEZ, J.A.; GUERRA-SANTOS, I. Una enfermedad lejana: la información sobre poliomielitis y síndrome post-polio en la prensa hispano-lusa, 19952009. História, Ciências, Saúde - Manguinhos, 22(3), p. 985-1005, $2015 \mathrm{~b}$.

SANCHEZ FREIRE, Pedro; HERRERA MARTINEZ, Manuela; RODRIGUEZ RIVAS, Migdalia. ¿Sabes qué es la epigenética? Medicentro Electrónica, Santa Clara , v. 17, n. 1, p. 40-42, marzo $2013 \quad$ Disponible en $<$ http://scielo.sld.cu/scielo.php?script=sci_arttext\&pid=S1029-

$30432013000100008 \& \operatorname{lng}=$ es\&nrm=iso>. accedido en 29 nov. 2020. 